Miroslava Mikusova - Jamshid Abdunazarov - Joanna Zukowska - Alisher Usmankulov

\title{
DESIGNING OF PARKING SPACES TAKING INTO ACCOUNT THE PARAMETERS OF DESIGN VEHICLES IN RUSSIA
}

Nowadays, in all the cities, there is an acute problem of a lack of parking spaces. The number of vehicles are becoming more and more larger, not only in megacities, but in small cities of the country, as well and there are no more parking places - the pace of solving the problem is several times slower than the rate of the transport growth among the citizens. The article is dedicated to the determination of the optimum sizes parking place for designing vehicles on a parking space, which is an element of the roads. The optimum amount parking places are determined on examples of the passenger cars and trucks. The results of research on dimensioning of parking spaces and recommendations to use the results for design of objects of transportation infrastructure are presented. According to the research, authors included the term "design vehicle" and gave its definition. The authors developed a template for 7 types of design vehicles and their sizes and also recommended sizes for longitudinal parking for each of their design vehicles. The optimum parking plot angles are determined, as well.

Keywords: trajectory, parking space, design vehicle, software Auto TURN, turning radius of vehicles

\section{Introduction}

Trends in the size of cars in traffic flow and an acute shortage of parking space require a more careful attitude towards design of the size of a parking place and parking space. Unfortunately, design of parking does not take into account the composition of the traffic flow that takes shape on a specific road, transport infrastructure object (requirements are obvious here, in the USA where the size of cars is larger than in Europe, the size of parking space is larger), duration of parking is not taken into account; short-term parking near shops, banks, etc., requires more space for manoeuvring upon arrival and departure from the parking space than during the long-term parking). The most acute problem manifested itself when a ban was imposed on the transit movement of vehicles weighing more than 12 tons during the daytime along the Moscow Ring Road (Resolution of the Mayor of Moscow, dated November 15, 2012 No. 650-PP "On Amendments to Legal Acts of the Government of Moscow" [1]). According to the Moscow mayor's office, more than 150 thousand trucks with a maximum weight of more than 3.5 tons are moving through the city streets during the daytime. About 40 thousand trucks are arriving daily from other regions.

At the Moscow Ring Road, large trucks make up 30\% of the flow, half of which are transit and do not serve the needs of the capital [2]. At that time, there was no experience in designing parking place for cars arriving in Moscow or following in transit.
In the domestic regulatory and procedural documents, the dimensions of parking spaces for the road infrastructure facilities are defined in the Methodological Recommendations of the SRC MDRS MIA [3], IRM 218.4.005-20101 и SS P 52289-20042. The dimensions in these documents were copied from the Handbook for Automobile Transportation and Traffic Management [4] published in the USSR in 1981, which, in turn, was a translation of the American Road Traffic Management Handbook of 1965 and the recommendations given in the third edition of the Transportation and Traffic Engineering Handbook [5].

Requirements for parking geometry in regulatory documents contain ambiguous, sometimes contradictory information that may adversely affect the level of the road safety. Thus, in the "Methodological recommendations on the design and equipment of highways to ensure traffic safety" [6], the turning radius of a passenger car is $8 \mathrm{~m}$ and for a truck is $9-12 \mathrm{~m}$. When approximate calculation of the total area of coverage in parking place, including the area of manoeuvring and parking is done, it is recommended to proceed from the average area per one passenger car of $25 \mathrm{~m}^{2}$ and on a truck $40 \mathrm{~m}^{2}$. At the same time, in the album of typical projects "Cross-sectional profiles of highways passing through settlements" (TP503-0-47.86) [7], the average parking area for a truck should be $92.4 \mathrm{~m}^{2}$, not 40 $\mathrm{m}^{2}$, as stated in the methodological recommendations. The dimensions of the parking space, given in the Regulations for the placement of multifunctional zones of road service on roads [8-10], take into account the size of modern cars,

\footnotetext{
Miroslava Mikusova' ${ }^{1, *}$, Jamshid Abdunazarov ${ }^{2}, J_{0 a n n a} Z_{\text {ukowska }}{ }^{3}$, Alisher Usmankulov ${ }^{4}$

${ }^{1}$ Department of Road and Urban Transport, Faculty of Operation and Economics of Transport and Communications, University of Zilina, Slovakia

${ }^{2}$ Jizzakh Polytechnic Institute, Faculty of Auto Transport, Department of Land Transport Systems, Uzbekistan

${ }^{3}$ Faculty of Civil and Environmental Engineering, Gdansk University of Technology, Poland

${ }^{4}$ Jizzakh Polytechnic Institute, Faculty of Industrial Technologies, Jizzakh, Uzbekistan

*E-mail of corresponding author: miroslava.mikusova@fpedas.uniza.sk
} 
a

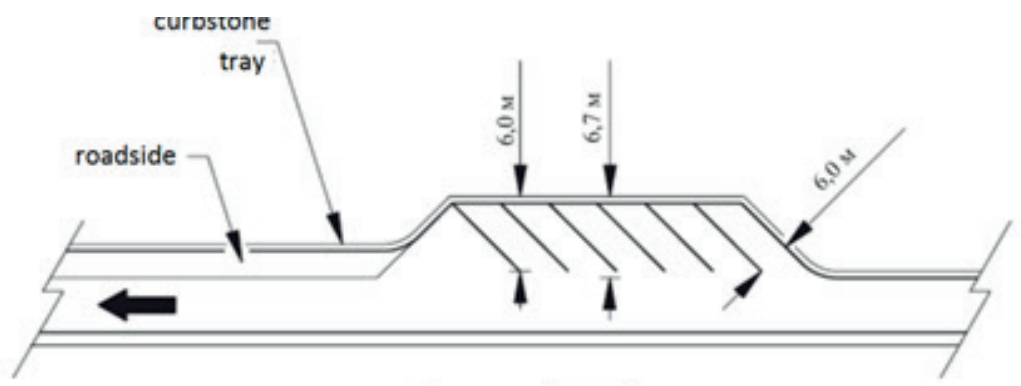

b

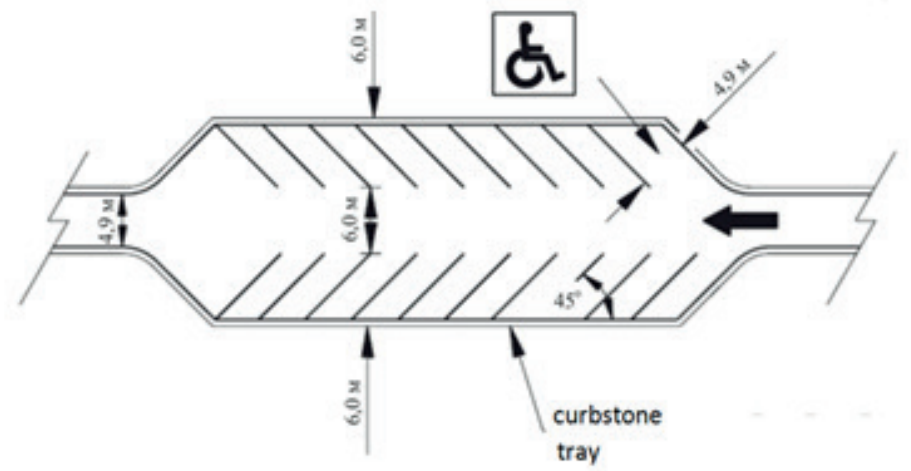

Figure 1 Schemes of planning of parking spaces for passenger cars with one-sided (a) and two-sided (b) placement

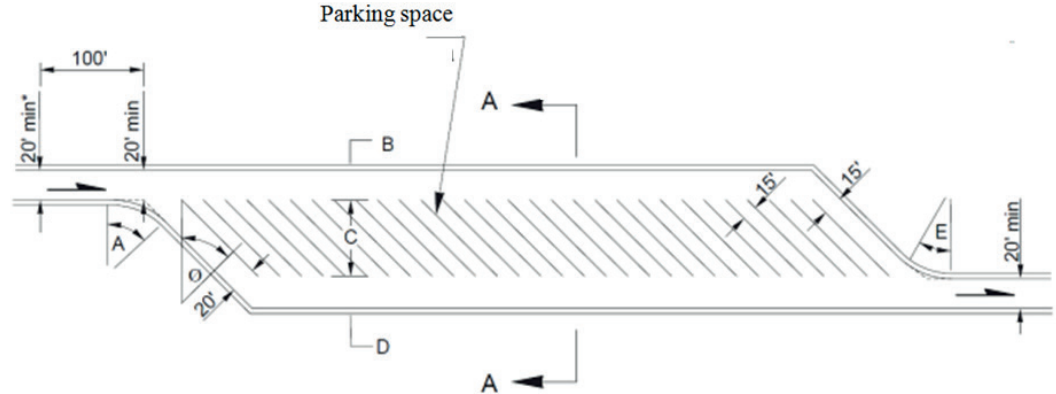

Figure 2 The fundamental planning of placement of the parking spaces for trucks, recommended in the US: $\phi$ - 30-45; $A$ - 25.9-3.0.5 m; B- 9.1-13.7m; $C$ - 15.2-18.8 m; D - 9.1-13.7 m; $E$ - 3.0.5-3.5.0 m.

but this is not enough to develop a complete planning solution, since the parking manoeuvres are not taken into account, and only the dimensions of the parking space are given.

The situation in the regulatory documents of Uzbekistan is similar. Since Uzbekistan was part of the USSR, it uses the same technical document that Russia used before, [3]. At the moment, technical documents, recommending the size of design vehicles, taking into account the current flow in the republic, have not been adopted. For example, the parameters (sizes) of trucks that were produced in the 70 s of the last century are still being used. The situation is similar in terms of the size of the parking spaces. At the moment, the republic uses the regulatory document, which requires updating based on time. The passenger car and truck placement schemes, used in the United States and the dimensions of parking spaces shown in Figure 1, provide more complete information. The planning solution for placing the parking spaces for trucks, which provides the simplest conditions for entering and leaving a parking space, recommended in the USA, is shown in Figure 2. The sizes on the scheme, presented in Figure 3, correspond to a parking angle of $45^{\circ}$, while it is indicated that at angles of $30^{\circ}$, the width of the passages can be reduced to $6.0 \mathrm{~m}$ and the width of each parking space - by $30 \mathrm{~cm}$. For large trucks, the length of the longitudinal parking space must be at least $41 \mathrm{~m}$ and width $5.2 \mathrm{~m}$. The same values are specified in the regulations of the United Arab Emirates for large trucks on parking spaces.

At the Department of Survey and design of roads MADI a research to justify the size of parking spaces for vehicles, taking into account the characteristics for modern traffic on the roads of the Russian Federation, has been conducted. The studies were conducted on category $1 \mathrm{~b}$ roads, as well as on city parking lots.

This research work included: monitoring parking manoeuvres, studying the real situation when setting up parking spaces and modelling parking manoeuvres of passenger cars and trucks, using the Auto TURN software, which allows simulating the movement and manoeuvring of vehicles at speeds up to $60 \mathrm{~km} / \mathrm{h}$, and also to model the three-dimensional movement on a 3D surface, localize modelling for various groups of vehicles; graphically represent the dynamic dimensions indicating the dynamic dimensions of the vehicles (external and internal wheels, characteristic points of the body); create vehicle reversal 


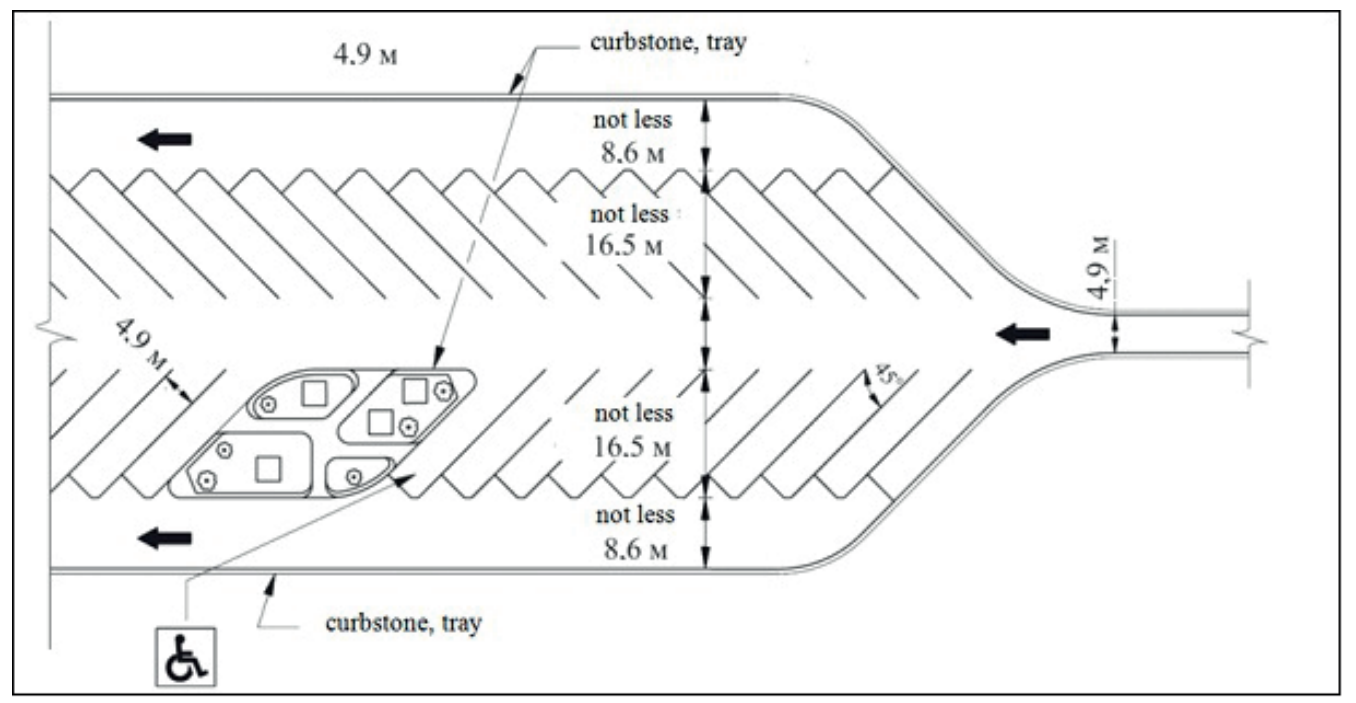

Figure 3 Scheme of parking spaces for trucks

patterns [11]. The AutoTURN is a CAD software released for the AutoCAD, MicroStation, BricsCAD platforms, developed and marketed by Transoft Solutions Inc. Among many things, it analyzes and models the maneuvering of a vehicle along a path

The parking space for vehicles includes parking space for a vehicle and a manoeuvring area, designed for the entrance to parking spaces, exit and setting cars. The dimensions of the parking space must ensure unhindered entry, opening the doors of vehicles, unloading or loading luggage, and then unimpeded exit without hitting other vehicles.

The dimensions of the car parking space determine its type and size (length, width, turning radius of the inner rear wheel, overhang, base and gauge). To be able to bypass and open the doors of the car, the parking dimensions should be $0.5 \mathrm{~m}$ larger than the corresponding dimensions of the designing vehicles [12].

The "Methodological guidelines for design and equipment of highways to ensure traffic safety" [13], indicated that parking at large recreation areas, at roadside catering establishments, motels and campgrounds should be placed between the highway and buildings with vehicle separation by types and sizes. Parking areas for trucks and passenger cars should be demarcated and a separate entrance to the appropriate temporary parking area should be provided for each type of vehicle.

In this case, passenger cars and buses are recommended to be on the left-hand side and trucks on the right in the direction of travel.

It is recommended to place the parking of trucks parallel to the axis of movement, while parking of passenger cars mainly should be arranged according to an oblique angle at an angle of $45-60^{\circ}$. For long stays in the parking place, as well as in cramped conditions, when the parking place has one exit, it is recommended to install vehicles perpendicular to the direction of the axis of movement. Recommendations are given for the designation of the average area of coverage for one vehicle, taking into account the area of the exit and entry zones and the area of the parking space itself.

Due to increase in the dynamic characteristics of vehicles, the requirements for the construction and design of roads are being improved. During the roads designing, it becomes necessary to introduce the concept of a "design vehicle". This term is defined differently. "A design vehicle is a vehicle used to determine the geometrical parameters of roads (minimum turning radii of the intersection at one level, turning radii, roundabout) affecting safety, capacity and cost of the intersection. This is a conditional transport unit, the parameters of which are used in the calculations of the pavement and its elements. A design vehicle is such a car, the mass, dimensions and dynamic qualities of which are used when designing a road. Parameters of the design vehicle, such as dimensions and the minimum turning radius, should be the same for majority of vehicles of the same class, which are supposed to be used for the movement of the designed road".

During the roads and parking spaces designing, it becomes necessary to determine the width of the path of overhang, the size of the manoeuvres space, and geometric parameters. This in each case requires the construction of the dynamic dimension of the design vehicles, which is a time-consuming process (especially for the road trains) and not it is sufficiently mastered by designers.

The lack of systematic reference material on these issues is often the cause of unreasonable design decisions, which either lead to an overestimation of the estimated costs of facilities or do not provide normal operating conditions for vehicles.

\section{Materials and methods}

To determine the width of the manoeuvring of parking spaces, the authors took into account the minimum turning radius of the design vehicle and its dynamic clearance. To do this, studies have been conducted that allowed to 


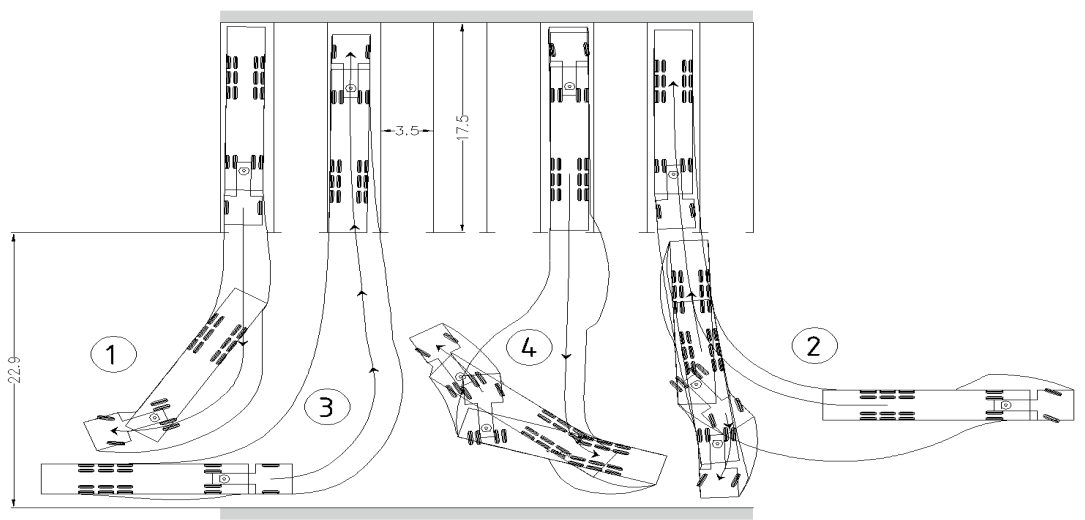

a)

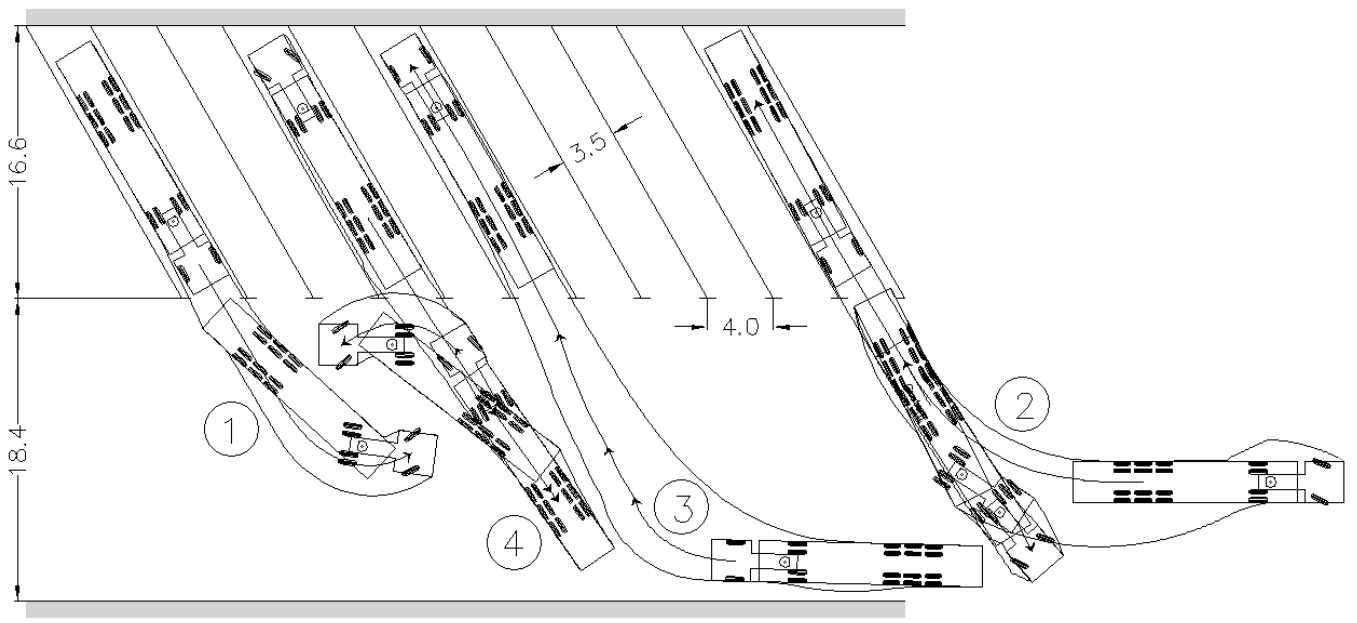

b)

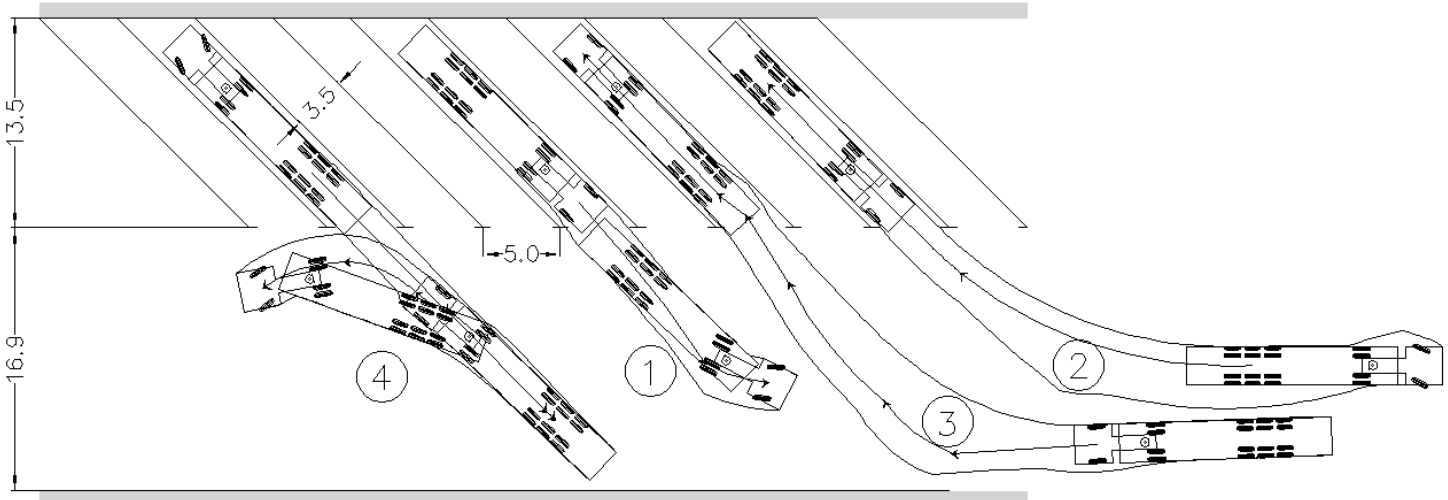

c)

Figure 4 Manoeuvring schemes for a train $\left(16.5 \mathrm{~m}^{2}\right)$ in a parking: a) the location of the parking space at an angle of $90^{\circ}$; b) the location of the parking space at an angle of $45^{\circ} ;$ c) the location of the parking space at an angle of $60^{\circ}$ (1-way forward; 2- backing; 3-forward ride; 4 - reversing)

determine these characteristics [14-16]. In the study, the width of the passage was determined as follows. When designing the parking space and the entrance of vehicles at parking spaces, the following schemes and provisions were applied in the calculations:

1 - The road train leaves the parking space in the forward direction;

2 - Auto train drives backward in a parking space;
3 - Road train drives forward;

4 - The road train leaves the parking space in reverse.

It was found that for reversing a large manoeuvring lane is needed than in other variants. This manoeuvre is a common parking method for the road train drivers. With this in mind, the width of the manoeuvring strip was determined. 


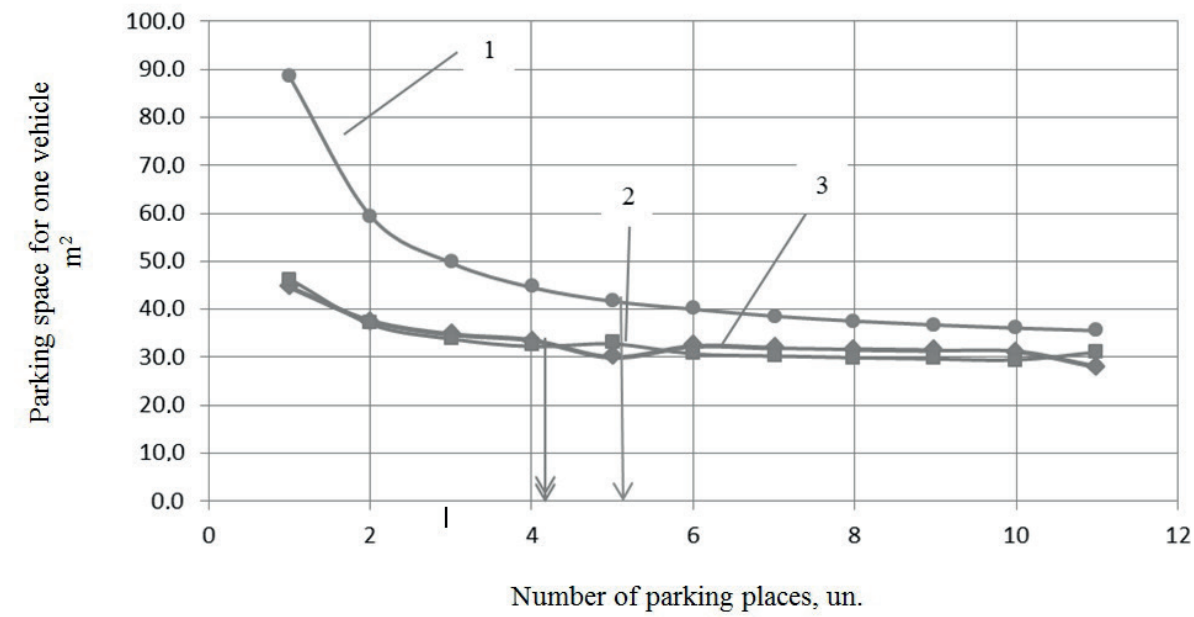

a)

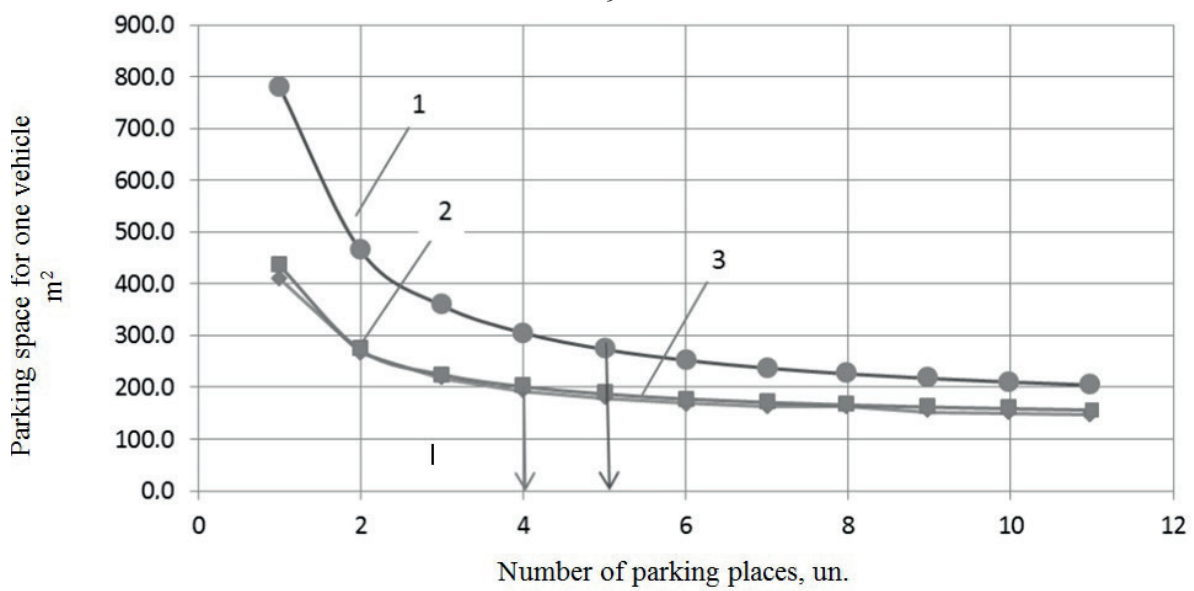

b)

Figure 5 The dependence of the area of parking space on the number of parking spaces for passenger cars: a) and for a train $16.5 \mathrm{~m}$ long; b) when set at the corners: $1-90^{\circ} ; 2-60^{\circ} ; 3-45^{\circ}$

The design vehicle made a manoeuvre at the location of a parking space at an angle of $90^{\circ}, 60^{\circ}$ and $45^{\circ}$ (see Figure 4). After each manoeuvre, the parking length, manoeuvring lane, and parking width were determined.

Studies have shown that for one passenger car, taking into account manoeuvring, $28.7 \mathrm{~m}^{2}$ of parking space is needed. For a road train length of $16.5 \mathrm{~m}$, this value is 143.1 $\mathrm{m}^{2}$ of area.

From Figure 5 it follows that with more than five parking spaces the area of parking space for one vehicle does not increase (depending on the angle). When the parking space is located at an angle of $90^{\circ}$ and if there are less than 5 parking spaces in the parking, the parking space is reduced by one car. At the location of parking spaces at angles of $60^{\circ}$ and $45^{\circ}$, the indicator is 4 parking spaces. Similar values are obtained for cars and for trucks. Proceeding from this, it can be concluded that, when parking places at an angle of $90^{\circ}$, designing less than five parking spaces is ineffective for any type of car and if placed at angles of $60^{\circ}$ or $45^{\circ}$, up to four parking spaces are considered ineffective.

From Figure 6 it follows that at the location of parking spaces at an angle of $45^{\circ}$ less parking space is required than at an angle of $60^{\circ}$ or $90^{\circ}$. These values do not affect the number of parking spaces; moreover, these values are the most effective indicator when manoeuvring cars on the parking site.

\section{Results and discussion}

Based on the above data, one can draw the following conclusions:

1. Less than 5 parking places at an angle of $90^{\circ}$ are economically inefficient for any type of vehicles;

2. When located at angles of $60^{\circ}$ or $45^{\circ}$, up to 4 parking places are considered to be economically inefficient.

The following types of design vehicles were recommended as the most frequently encountered on the roads for Russian Federation: passenger car (P); city bus (CB); bus (B); articulated bus (AB); truck (T); road train consisting of truck tractor and semi-trailer (A16); road train consisting of a truck and a trailer (A20). The main dimensions of the specified design vehicle are given in the Table 1 with a template for the design of curves in the plan with the minimum radius of the design vehicle: Figure 7 


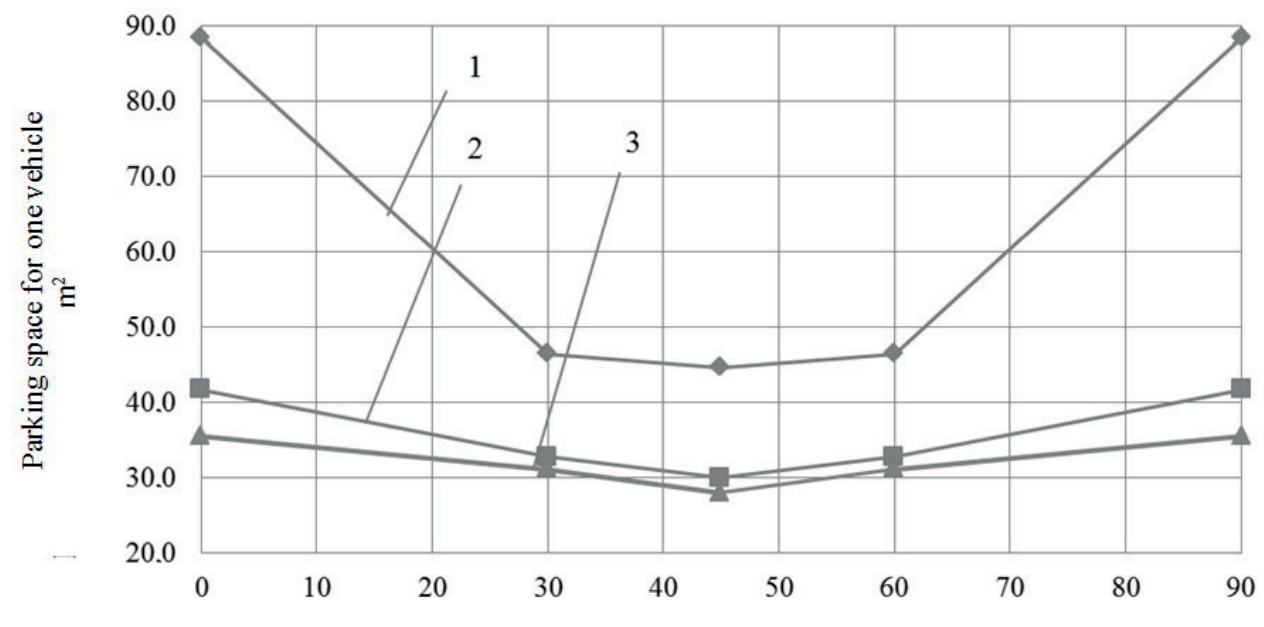

The angle of the parking space in relation to the driveway

a)

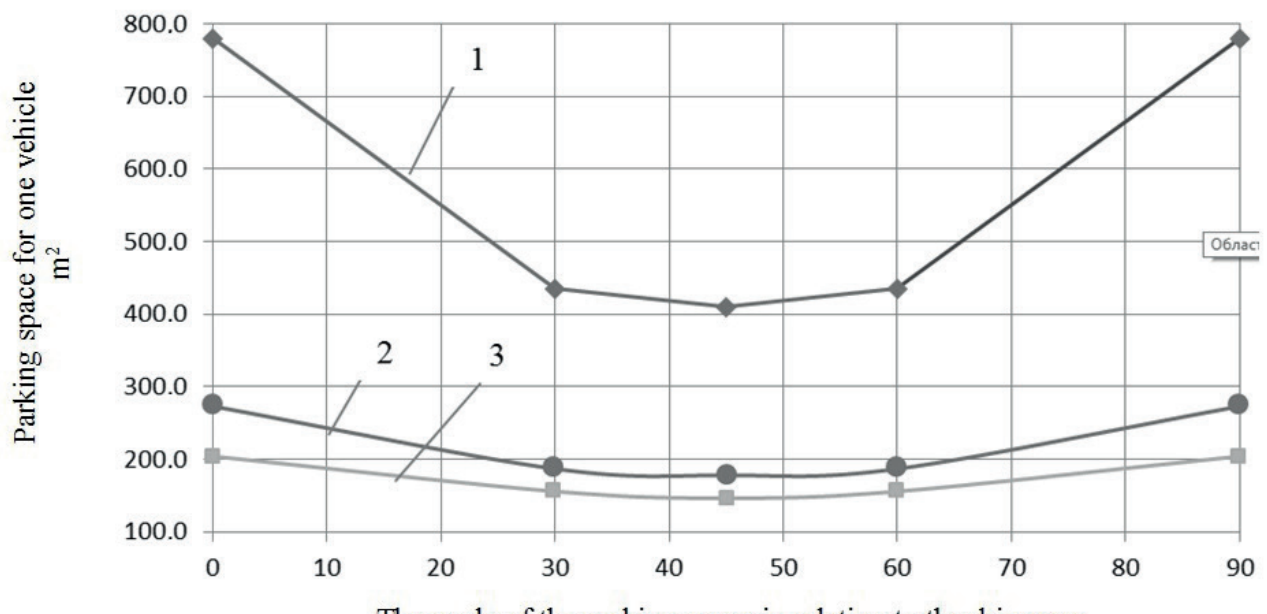

The angle of the parking space in relation to the driveway

b)

Figure 6 The required parking area at different angles of installation of vehicles and parking capacity: 1 - one vehicle; 2 - 5 vehicles; 3 - 11 vehicles [a) for passenger cars; b) for road trains with a length of $16.5 \mathrm{~m}$ ]

Table 1 Recommended size of the design vehicles

\begin{tabular}{|c|c|c|c|c|c|c|c|}
\hline \multirow{3}{*}{ Type of design vehicles } & & & \multirow{3}{*}{ Wheelbase, m } & \multicolumn{4}{|c|}{ Dimension, $\mathrm{m}$} \\
\hline & \multicolumn{2}{|c|}{ Designation } & & \multicolumn{2}{|c|}{ general } & \multicolumn{2}{|c|}{ overhang } \\
\hline & $\mathrm{RD}^{1)}$ & $\mathrm{TR}^{2)}$ & & length & width & front & rear \\
\hline Passenger car & $\mathrm{P}$ & $\mathrm{L}$ & 2.90 & 4.90 & 1.90 & 0.90 & 1.10 \\
\hline City bus & $\mathrm{CB}$ & $\mathrm{M}_{2}$ & 6.20 & 12.0 & 2.50 & 2.75 & 3.05 \\
\hline Bus & B & $\mathrm{M}_{3}$ & $6.90 / 1.30$ & 15.0 & 2.50 & 2.60 & 4.20 \\
\hline Articulated bus & $\mathrm{AB}$ & $\mathrm{M}_{3}$ & $5.96 / 6.05$ & 18.4 & 2.55 & 2.68 & 3.71 \\
\hline Truck & $\mathrm{T}$ & $\mathrm{N}_{3}$ & 6.80 & 12.0 & 2.50 & 1.50 & 3.70 \\
\hline Road train & A16 & $\mathrm{N}_{2}+\mathrm{O}_{4}$ & $3.80 / 7.02$ & 16.50 & 2.50 & 1.43 & 2.98 \\
\hline Road train & A20 & $\mathrm{N}_{3}+\mathrm{O}_{4}$ & $6.80 / 4.30$ & 19.80 & 2.50 & 1.50 & 0.70 \\
\hline
\end{tabular}

RD1) - vehicle designation adopted in the article.

TR2) - designation of cars in accordance with the Technical Regulations "On the safety of wheeled vehicles" (approved by the decision of the Commission of the Customs Union of 9 December 2011 No. 877) 
Table 2 Minimum turning radius of the design vehicle

\begin{tabular}{lccc}
\hline Type of design vehicles & Minimum turning radius, $\mathrm{m}$ & Minimum outer radius, $\mathrm{m}$ & Minimum inner radius, $\mathrm{m}$ \\
\hline Passenger car (P) & 6.55 & 6.85 & 4.42 \\
City bus (C) & 9.20 & 10.54 & 5.40 \\
Bus (B) & 10.32 & 11.52 & 6.40 \\
Articulated bus (A) & 13.12 & 14.21 & 10.10 \\
Truck (T) & 11.07 & 11.82 & 6.15 \\
Road train (A16) & 9.69 & 10.19 & 6.20 \\
Road train (A20) & 12.06 & 12.63 & 8.50 \\
\hline
\end{tabular}

a.

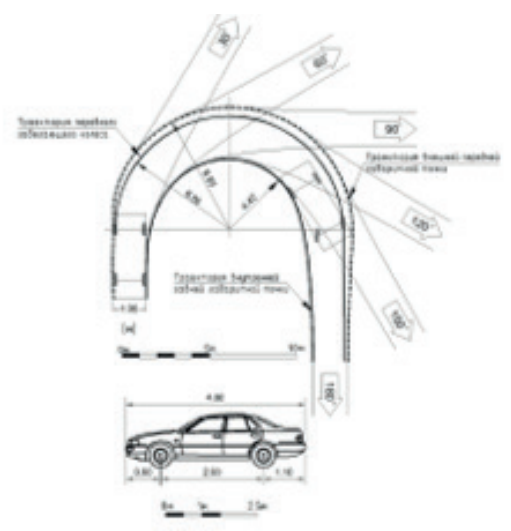

c.

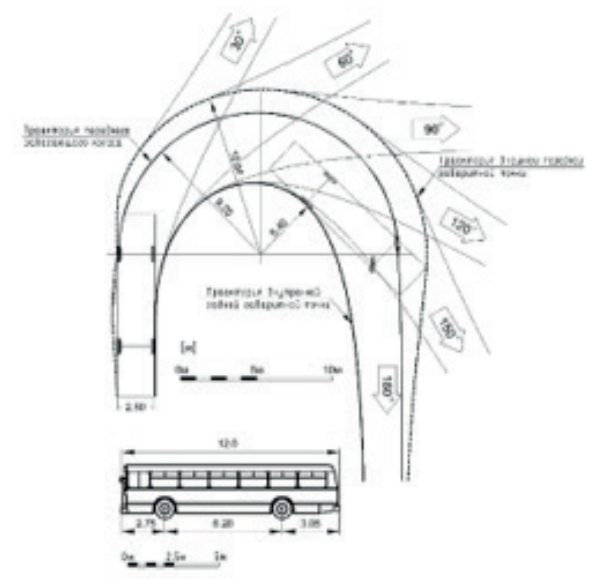

i.

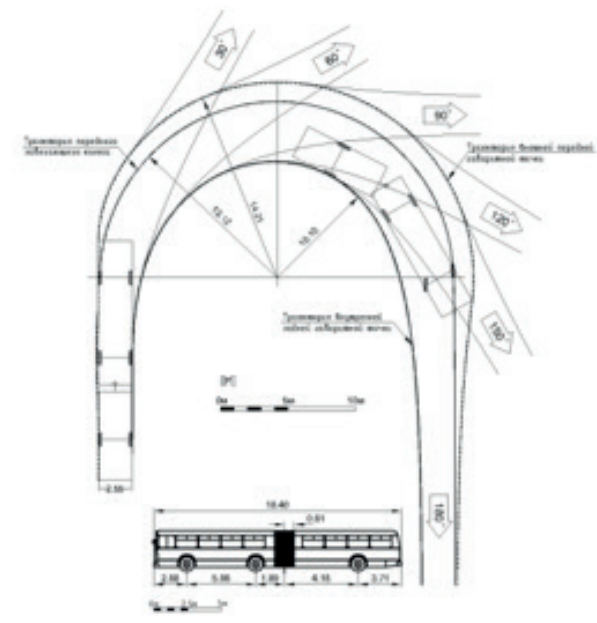

b.

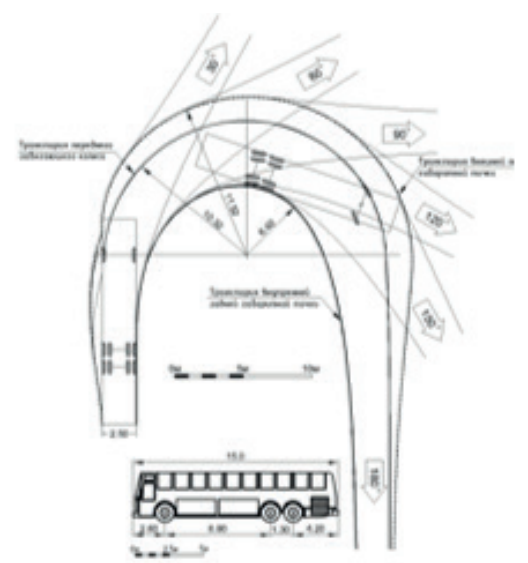

d.

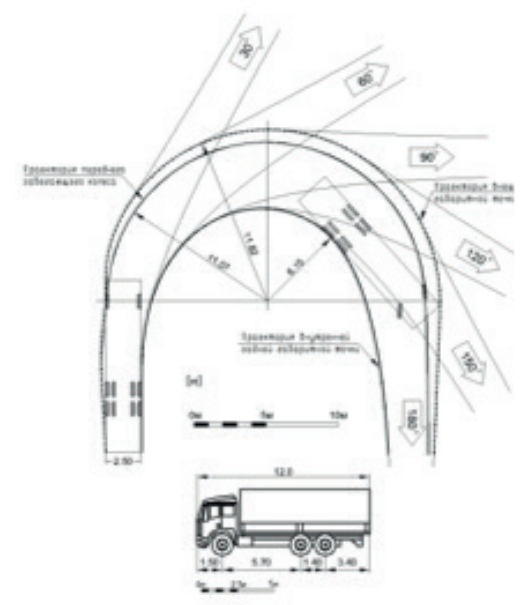

f.

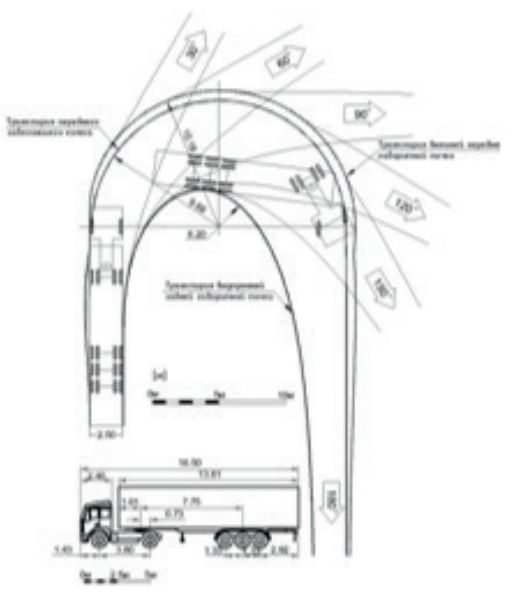

Figure 7 Template for the design of curves in the plan with the minimum radius of the design vehicle: a) passenger car $(P) ; b)$ city bus $(C B) ; c)$ bus $(B) ; d)$ truck $(T) i)$ articulated bus $(A B) ; f)$ road train (A16) 


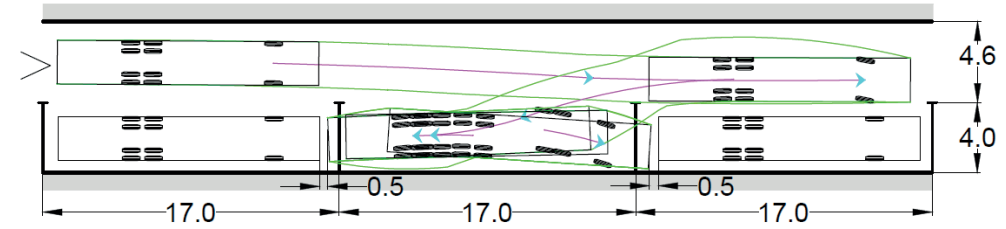

a)

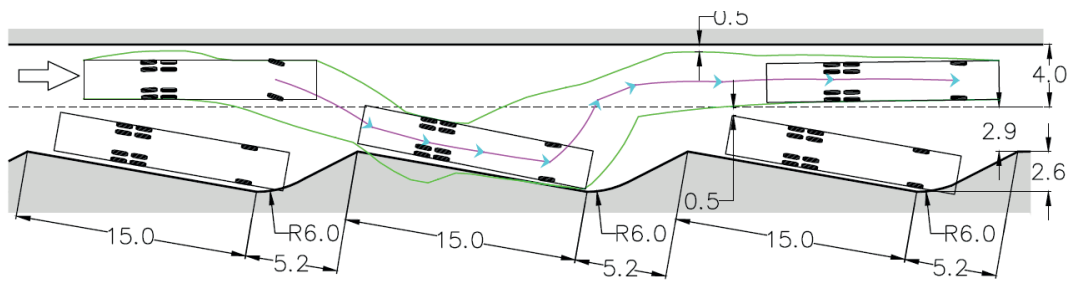

b)

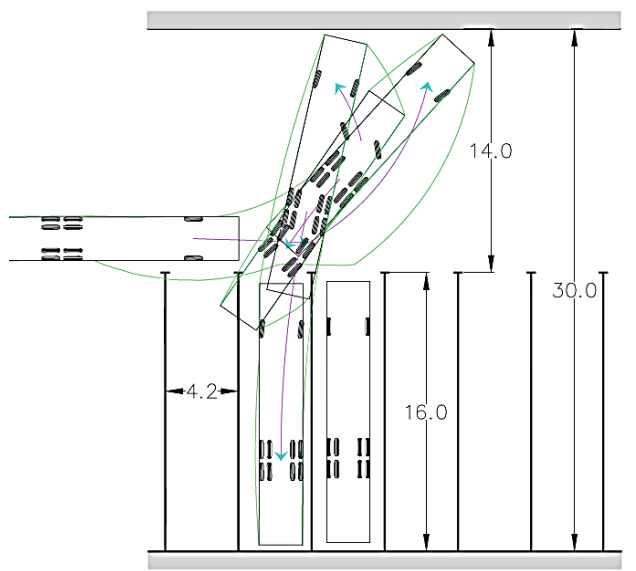

c)

Figure 8 Scheme and dimensions of parking spaces for bus: a) when parallel; b) saw tooth; c) perpendicular placement in relation to the driveway or manoeuvring zone. A similar scheme is proposed for other type of buses

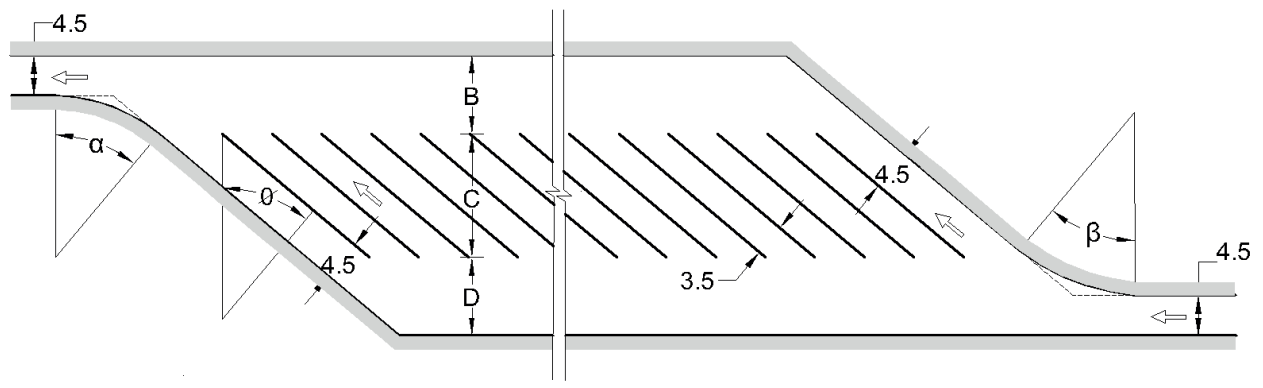

Figure 9 Elements of breakdown of parking space for trucks $\alpha$ - $\beta$ - parking angle; $\varnothing$ - vehicle installation angle; $B$ - $D$ - manoeuvring strip; $C$ - parking module length

[17], the minimum turning radius - in the Table 2. Scheme and dimensions of parking spaces for bus are given in Figure 8.

The resulting sizes of parking spaces and the scheme of their breakdown are given in Table 3. Recommended lengths of parking spaces for longitudinal placement of design vehicles are presented in Table 4 . Considering the foreign experience of organizing parking spaces for largesized vehicles, which provides for entry and exit to parking without reversing (Figure 9), as a result of research, it is recommended to take the dimensions of parking spaces in accordance with values in Table 5 . 
Table 3 Dimensions and average areas of one parking space

\begin{tabular}{|c|c|c|c|c|c|c|c|c|c|c|c|}
\hline \multirow[b]{2}{*}{$\begin{array}{c}\text { Vehicle } \\
\text { installation } \\
\text { angle, degree }\end{array}$} & \multicolumn{9}{|c|}{ Sizes of elements, m } & \multicolumn{2}{|c|}{ Average area for 1 vehicle, $\mathrm{m}^{2}$} \\
\hline & $\mathrm{a}$ & $\mathrm{b}$ & $\mathrm{c}$ & $d$ & $\mathrm{e}$ & $\mathrm{f}$ & $\mathrm{g}$ & $\mathrm{h}$ & $\mathrm{i}$ & $\begin{array}{c}\text { without } \\
\text { maneuvering }\end{array}$ & $\begin{array}{c}\text { with } \\
\text { maneuvering }\end{array}$ \\
\hline 1 & 2 & 3 & 4 & 5 & 6 & 7 & 8 & 9 & 10 & 11 & 12 \\
\hline \multicolumn{12}{|c|}{ One-way car parking (P) } \\
\hline 90 & 5.0 & 7.0 & 17.0 & 11.5 & 0.5 & 6.0 & 2.5 & 2.5 & 0.5 & 12.5 & 28.7 \\
\hline 60 & 5.2 & 4.2 & 14.6 & 8.9 & 0.5 & 3.2 & 2.5 & 2.9 & 0.5 & 15.1 & 25.8 \\
\hline 45 & 4.8 & 4.0 & 13.6 & 8.3 & 0.5 & 3.0 & 2.5 & 3.5 & 0.5 & 16.8 & 29.0 \\
\hline \multicolumn{12}{|c|}{ Two-way car parking (P) } \\
\hline 90 & 5.0 & 8.0 & 18.0 & 12.5 & 0.5 & 7.0 & 2.5 & 2.5 & 0.5 & 12.5 & 22.5 \\
\hline 60 & 5.2 & 5.2 & 15.6 & 9.9 & 0.5 & 4.2 & 2.5 & 2.9 & 0.5 & 15.1 & 22.6 \\
\hline 45 & 4.8 & 5.0 & 14.6 & 9.3 & 0.5 & 4.0 & 2.5 & 3.5 & 0.5 & 16.8 & 25.5 \\
\hline \multicolumn{12}{|c|}{ Truck Parking (T) } \\
\hline 90 & 13.0 & 16.1 & 42.1 & 28.6 & 0.5 & 15.1 & 3.5 & 3.5 & 0.5 & 45.5 & 100.1 \\
\hline 60 & 11.8 & 12.4 & 36.0 & 23.7 & 0.5 & 11.4 & 3.5 & 4.0 & 0.5 & 47.2 & 94.8 \\
\hline 45 & 10.5 & 8.7 & 29.7 & 18.7 & 0.5 & 7.7 & 3.5 & 5.0 & 0.5 & 52.5 & 93.5 \\
\hline \multicolumn{12}{|c|}{ City bus parking (CB) } \\
\hline 90 & 13.0 & 16.1 & 42.1 & 28.6 & 0.5 & 15.1 & 3.5 & 3.5 & 0.5 & 45.5 & 100.1 \\
\hline 60 & 11.8 & 12.4 & 36.0 & 23.7 & 0.5 & 11.4 & 3.5 & 4.0 & 0.5 & 47.2 & 94.8 \\
\hline 45 & 10.5 & 8.7 & 29.7 & 18.7 & 0.5 & 7.7 & 3.5 & 5.0 & 0.5 & 52.5 & 93.5 \\
\hline \multicolumn{12}{|c|}{ Bus parking (B) } \\
\hline 90 & 16.0 & 19.0 & 51.0 & 34.5 & 0.5 & 18.0 & 3.5 & 3.5 & 0.5 & 56.0 & 120.7 \\
\hline 60 & 14.3 & 16.1 & 44.7 & 29.9 & 0.5 & 15.1 & 3.5 & 4.0 & 0.5 & 57.2 & 119.6 \\
\hline 45 & 12.4 & 11.7 & 36.5 & 23.6 & 0.5 & 10.7 & 3.5 & 5.0 & 0.5 & 62.0 & 118.0 \\
\hline \multicolumn{12}{|c|}{ Articulated bus parking (AB) } \\
\hline 90 & 19.5 & 25.1 & 64.1 & 44.1 & 0.5 & 24.1 & 3.5 & 3.5 & 0.5 & 68.3 & 154.3 \\
\hline 60 & 17.3 & 20.3 & 54.9 & 37.1 & 0.5 & 19.3 & 3.5 & 4.0 & 0.5 & 69.2 & 148.4 \\
\hline 45 & 14.9 & 18.5 & 48.3 & 32.9 & 0.5 & 17.5 & 3.5 & 5.0 & 0.5 & 74.5 & 164.5 \\
\hline \multicolumn{12}{|c|}{ Road train parking (A16) } \\
\hline 90 & 17.5 & 23.9 & 58.9 & 40.9 & 0.5 & 22.9 & 3.5 & 3.5 & 0.5 & 61.3 & 143.1 \\
\hline 60 & 16.6 & 18.9 & 52.1 & 35.0 & 0.5 & 17.9 & 3.5 & 4.0 & 0.5 & 66.4 & 140.0 \\
\hline 45 & 13.5 & 17.4 & 44.4 & 30.4 & 0.5 & 16.4 & 3.5 & 5.0 & 0.5 & 67.5 & 152.0 \\
\hline \multicolumn{12}{|c|}{ Road train parking (A20) } \\
\hline 90 & 21.0 & 33.0 & 75.0 & 53.5 & 0.5 & 32.0 & 3.5 & 3.5 & 0.5 & 73.5 & 187.2 \\
\hline 60 & 18.6 & 23.8 & 61.0 & 41.9 & 0.5 & 22.8 & 3.5 & 4.0 & 0.5 & 74.4 & 167.6 \\
\hline 45 & 16.0 & 21.1 & 53.1 & 36.6 & 0.5 & 20.1 & 3.5 & 5.0 & 0.5 & 80.0 & 183.0 \\
\hline
\end{tabular}

Table 4 The length of parking spaces for longitudinal design vehicles

\begin{tabular}{|c|c|c|c|c|c|c|c|}
\hline \multirow{2}{*}{ Design vehicle } & \multirow{2}{*}{$\begin{array}{l}\text { Passenger car } \\
\text { (P) }\end{array}$} & \multirow{2}{*}{ Truck $(T)$} & \multicolumn{3}{|c|}{ Buses } & \multicolumn{2}{|c|}{ Road Train } \\
\hline & & & $(\mathrm{CB})$ & (B) & $(\mathrm{AB})$ & (A16) & (A20) \\
\hline $\begin{array}{l}\text { Parking space } \\
\text { length, m }\end{array}$ & 6.0 & 14.0 & 14.0 & 17.0 & 22.5 & 20.0 & 24.0 \\
\hline
\end{tabular}


Table 5 Sizes of parking spaces at different corners of the parking of trucks

\begin{tabular}{|c|c|c|c|c|c|}
\hline \multicolumn{3}{|c|}{ Set angle, degree } & \multicolumn{3}{|c|}{ Sizes of parking spaces, m (see Figure 9) } \\
\hline$\varnothing$ & $\alpha$ & $\beta$ & $\mathrm{B}$ & $\mathrm{C}$ & $\mathrm{D}$ \\
\hline \multicolumn{6}{|c|}{ A16 } \\
\hline 30 & 30 & 30 & 7.5 & 12.0 & 7.5 \\
\hline 35 & 35 & 35 & 8.5 & 13.0 & 8.5 \\
\hline 40 & 40 & 40 & 8.7 & 13.5 & 8.7 \\
\hline 45 & 45 & 45 & 9.5 & 15.5 & 9.5 \\
\hline \multicolumn{6}{|c|}{$\mathrm{A} 20$} \\
\hline 30 & 30 & 30 & 8.0 & 13.0 & 8.0 \\
\hline 35 & 35 & 35 & 9.0 & 15.5 & 9.0 \\
\hline 40 & 40 & 40 & 9.2 & 16.5 & 9.2 \\
\hline 45 & 45 & 45 & 10.0 & 17.7 & 10.0 \\
\hline
\end{tabular}

For highways, where trucks and road trains predominate as part of the traffic flow, it is recommended to the plan parking spaces with a transverse arrangement so that trucks do not need the turning manoeuvre or movement with minimum radii. Design of diagonal parking may vary depending on the angle at which the vehicles are located. To determine the size of the diagonal parking spaces for trucks, the authors created a design vehicle model and modelled the movement path of the design vehicle and determined the dynamic size, as well. With this in mind, the main dimensions of the parking lot were determined (Figure 9). Using the above approach, the diagonal parking sizes were determined at an angle from $30^{\circ}$ to $45^{\circ}$. The planning of the parking space includes the following actions: alternative placement of parking spaces within the parking lot, modelling using the dynamic dimensions of the design vehicle of entrances to the parking space and exits. A necessary element of the traffic organization in the parking lot and design of the parking space, is organization of unimpeded passage of vehicles pass parking spaces with a width of 4.5 meters. The minimum radius for entering the parking lot should be at least $26 \mathrm{~m}$ and at the exit - at least $30 \mathrm{~m}$. Dimensions of the parking spaces at different parking angles are presented in Table 5 .

\section{Conclusions}

During the studying of the parking lots sizes the authors found that the previously adopted regulatory documents recommended dimensions for the existing traffic flow in the twentieth century. Regulatory documents contained ambiguous, sometimes contradictory information, which is contrary to objectives of the road safety and its convenience. Dimensions of the parking space, recommended by the author, differ from the current regulatory documents in the direction of reducing the area for a parking space. This is due to the fact that in modern vehicles dynamic indicators are optimized and require less space for manoeuvring.

\section{References}

[1] Information and legal portal Garant [online]. [Viewed 2019-27-01]. Available from: http://www.garant.ru/hotlaw/moscow /430367

[2] BURANOV, I. Mayor shifted the burden of responsibility to the region. Kommersant. 2012, 218(5003). ISSN 1563-6380.

[3] Monitoring compliance with the norms, rules and standards when designation and construction of roadside facilities (service facilities). Methodical recommendations. Moscow: SIC STSI of the Ministry of Internal Affairs of Russia. 2004.

[4] RANKIN, V. U. Automobile transportations and the organization of traffic. Reference book. Moscow: Transport, 1981.

[5] BAERWALD, J. E. Transportation and traffic engineering handbook. 3. ed. Washington, D. C.: Institute of Traffic Engineers, 1965.

[6] Design and equipment of highways to ensure traffic safety. Methodical recommendations. Moscow: Transport, 1983.

[7] ABDUnazarov, J. N. Design vehicle for the design of roads (in Russian). Bulletin of the Moscow Automobile and Highway State Technical University (MADI) [online]. 2013, 3(34), p. 81a-84 [accessed 2019-21-11]. ISSN 2079-1364. Available from: https://elibrary.ru/item.asp?id=20164670 
[8] Regulations for the placement of multifunctional road zones of the service on the highways of the State company "Russian highways" (approved by the order of the State company "Russian highways" June 24, 2013, No. 114) [online]. [Viewed 2018-07-12]. Available from: http://www.rhighways.ru/for_investor/road_service/multifunctionalroad_service_ area

[9] POSPElOV, P. I., SHIT, B. A., ABDUNAZAROV, J. N., Designing of parking spaces on car parking (in Russian). Science and Engineers for Roads [online]. 2016, 2(76), p. 6-10 [accessed 2019-21-11]. ISSN 1993-8543. Available from: https://elibrary.ru/item.asp?id=26289975

[10] MIKUSOVA, M., ABDUNAZAROV, J. Modelling of vehicles movements for the design of parking spaces. In: Computational Collective Intelligence. ICCCI 2019. Lecture Notes in Computer Science. NGUYEN N., CHBEIR R., EXPOSITO E., ANIORTE P., TRAWINSKI B. (Eds). Vol 11684. Cham: Springer, 2019.

[11] Auto TURN. Advanced vehicle simulations [online]. [Viewed 2018-08-10]. Available from: http://store.softline.ru/ transoft/transoft-autoturn.

[12] Help for guests. Guidelines [online]. [Viewed 2019-08-02]. Available from: http://www.gosthelp.ru

[13] The Methodical recommendations on designing and equipping the highways for road safety. Minavtodor RSFSR, M.: Transport, 1983.

[14] ABDUNAZAROV, J. N. Modelling of the movement of the design vehicles on parking space (in Russian). Science and Engineers for Roads. [online]. 2018, 2(84), p. 10-11 [accessed 2019-21-11]. ISSN 1993-8543. Available from: https://elibrary.ru/item.asp?id=35225761

[15] MIKUSOVA, M., GNAP, J.: Experiences with the implementation of measures and tools for road safety. In: XII Congreso de Ingenieria del Transporte CIT 2016 [online]. Valencia, Spain: Universidad Politechnica de Valencia, 2016. ISBN 9788460899600, p. 1632-1638. Available from: https://doi.org/10.4995/CIT2016.2015.2555

[16] MIKUSOVA, M., ABDUNAZAROV, J., ZUKOWSKA, J.: Modelling of the movement of design vehicles on parking space for designing parking. In: 19th International Conference on Transport Systems Telematics TST 2019: Development of Transport by Telematics [online]. Vol. 1049. Heidelberg: Springer, 2019. ISBN 978-3-030-27546-4, eISSN 978-3-030-27547-1, p. 188-210. Available from: https://doi.org/10.1007/978-3-030-27547-1_15

[17] ABDUNAZAROV, J. N., MAMARASUlOVA, M. N., Recommended parameters of design vehicles for the Russian Federation (in Russian). Young Scientist [online]. 2016, 7(2), p. 26-29 [accessed 2019-21-11]. ISSN 2072-0297. Available from: https://moluch.ru/archive/111/27588 